\title{
Signatures of interplanetary transients behind shocks and their associated near-surface solar activity
}

\author{
S. Bravo, X. Blanco-Cano \\ Instituto de Geofisica, Universidad Nacional Autónoma de México, Coyoacán, D.F., 04510 Mexico \\ Received: 13 March 1997 / Revised: 3 November 1997 / Accepted: 5 November 1997
}

\begin{abstract}
Interplanetary transients with particular signatures different from the normal solar wind have been observed behind interplanetary shocks and also without shocks. In this paper we have selected four well-known transient interplanetary signatures, namely: magnetic clouds, helium enhancements and bidirectional electron and ion fluxes, found in the solar wind behind shocks, and undertaken a correlative study between them and the corresponding solar observations. We found that although commonly different signatures appear in a single interplanetary transient event, they are not necessarily simultaneous, that is, they may belong to different plasma regions within the ejecta, which suggests that they may be generated by complex processes involving the ejection of plasma from different solar regions. We also found that more than $90 \%$ of these signatures correspond to cases when an $\mathrm{H} \alpha$ flare and/or the eruption of a filament occurred near solar central meridian between 1 and 4 days before the observation of the disturbance at $1 \mathrm{AU}$, the highest association being with flares taking place between 2 and 3 days before. The majority of the $\mathrm{H} \alpha$ flares were also accompanied by soft X-ray events. We also studied the longitudinal distribution of the associated solar events and found that between $80 \%$ and $90 \%$ of the interplanetary ejecta were associated with solar events within a longitudinal band of $\pm 30^{\circ}$ from the solar central meridian. An eastwest asymmetry in the associated solar events seems to exist for some of the signatures. We also look for coronal holes adjacent to the site of the explosive event and find that they were present almost in every case.
\end{abstract}

Key words. Interplanetary physics · Interplanetary shocks - Solar wind plasma $\cdot$ Solar physics $\cdot$ Flares and mass ejections

Correspondence to: $\mathrm{S}$. Bravo

e-mail: sbravo@tonatiuh.igeofcu.unam.mx

\section{Introduction}

The origin of large-scale transient phenomena in the solar wind was initially attributed to flares at the Sun [see for instance Hundhausen (1972) and the review by Gosling (1993)], but later also associations with prominence eruptions were found (e.g. Joselyn and MacIntosh, 1981). However, many interplanetary (IP) transient shocks are not associated with a flare or a prominence eruption. After the discovery of coronal mass ejections (CMEs) (e.g. Tousey, 1973; Gosling et al., 1974) a combined study of the Helios spacecraft solar wind measurements and the observations of the Solwind coronagraph on board the P78-1 satellite showed that IP shocks were virtually always associated with CMEs (Sheeley et al., 1985), although the majority of CMEs are not associated with IP shocks. CMEs are sometimes associated with near-surface activity such as the eruption of a prominence and/or a flare, being more commonly associated with prominences (e.g., Wagner, 1984; Webb and Hundhausen, 1987). A statistical study carried out by Harrison (1994) of the CMEs observed by the Solar Maximum Mission (SMM) satellite in 1986 and 1987 showed that only $14 \%$ of them were associated with an X-ray flare within a temporal window of $\pm 2 \mathrm{~h}$ centred on the first moment of observation of the CME and within $50^{\circ}$ from the limb. In the Solwind/Helios study, which includes only those CMEs associated with IP shocks, this percentage was higher, but only $49 \%$ of the CMEs associated with IP shocks occurred in combination with flares. On the other hand, the use of interplanetary scintillation (IPS) of celestial radio sources during more than 1 year to track major solar wind disturbances back to the Sun showed that coronal holes were always found in the solar source region of the disturbances (Hewish and Bravo, 1986). Less than half of the transient disturbances $(47 \%)$ were associated with the occurrence of a solar flare or the eruption of a prominence, and so we suggested that the origin of IP 
Table 1. Transient IP events used in this study and their solar association

\begin{tabular}{|c|c|c|c|c|c|c|c|c|c|}
\hline \multicolumn{7}{|c|}{ IP signature } & \multicolumn{3}{|l|}{ Solar association } \\
\hline \multirow[t]{2}{*}{ no. } & date & $\mathrm{MC}$ & $\mathrm{A}(\mathrm{He})$ & $\mathrm{BDE}$ & BDI & ref. & $\mathrm{F} / \mathrm{P}$ & $\mathrm{X}$ & $\mathrm{CH}$ \\
\hline & 1967 & & & & & & & & \\
\hline 1 & $13 / 01$ & $\mathrm{Y}$ & & & & 15 & $\mathbf{P}(12)$ N43 165 E03 & - & \\
\hline \multirow[t]{2}{*}{2} & $15 / 02$ & $\mathrm{~N}$ & $\mathrm{Y}$ & & & 12 & $\mathbf{F}(13) 1751$ N20 W13 & $\mathrm{S}$ & \\
\hline & & & & & & & 3B/ P(14) N30 120 W08 & & \\
\hline \multirow[t]{3}{*}{3} & $29 / 12$ & Y & & & & 18 & $\mathbf{F}(27) 1943 \mathrm{~S} 16 \mathrm{~W} 10$ & & \\
\hline & & & & & & & $1 \mathrm{~B} / \mathbf{P}(28) \mathrm{S} 28253 \mathrm{C}$ & & \\
\hline & 1969 & & & & & & & & \\
\hline \multirow[t]{2}{*}{4} & $10 / 02$ & $\mathrm{Y}$ & & & & 15 & $\mathbf{F}(07) 0523 \mathrm{~N} 01 \mathrm{~W} 21$ 1B & $\mathrm{S}$ & \\
\hline & 1971 & & & & & & & & \\
\hline 5 & $03 / 04$ & $\mathrm{Y}$ & $\mathrm{Y}$ & & & 1 & $\mathbf{F}(01) 1319 \mathrm{~S} 17 \mathrm{~W} 14$ 3N & $\mathrm{S}$ & \\
\hline \multirow[t]{2}{*}{6} & $17 / 05$ & $\mathrm{~N}$ & $\mathrm{Y}$ & & & 2 & $\mathbf{F}(14) 1411$ N03 E15 3B & $\mathrm{L}$ & \\
\hline & 1972 & & & & & & & & \\
\hline 7 & $06 / 03$ & $\mathrm{~N}$ & $\mathrm{Y}$ & & & 1 & $\mathbf{P}(3) \mathrm{S} 20241 \mathrm{E} 11$ & - & \\
\hline 8 & $17 / 04$ & $\mathrm{~N}$ & $\mathrm{Y}$ & & & 1 & $\mathbf{P}(14)$ S20 97 W28 & - & \\
\hline 9 & $18 / 04$ & & Y & & & 1 & $\mathbf{F}(14) 1950 \mathrm{~S} 12 \mathrm{~W} 32$ 1B & $\mathrm{S}$ & \\
\hline 10 & $20 / 04$ & $\mathrm{~N}$ & $\mathrm{Y}$ & & & 1 & $\mathbf{P}(18)$ N16 349 E13 & - & \\
\hline 11 & $15 / 05$ & $\mathrm{~N}$ & $\mathrm{Y}$ & & & 1 & $\mathbf{P}(13) \mathrm{S} 2513$ E17 & - & \\
\hline 12 & $18 / 10$ & $\mathrm{~N}$ & Y & & & 1 & $\mathbf{P}(16) \mathrm{S} 24124 \mathrm{C}$ & - & \\
\hline \multirow[t]{2}{*}{13} & $31 / 10$ & $\mathrm{Y}$ & $\mathrm{Y}$ & & & 1 & $\mathbf{F}(30) 0735 \mathrm{~S} 11$ W05 1N & $\mathrm{L}$ & \\
\hline & 1973 & & & & & & & & \\
\hline 14 & $13 / 04$ & $\mathrm{Y}$ & Y & & & 1 & $\mathbf{F}(10) 1315 \mathrm{~S} 12 \mathrm{~W} 202 \mathrm{~N}$ & $\mathrm{~L}$ & \\
\hline 15 & $14 / 04$ & $\mathrm{~N}$ & $\mathrm{Y}$ & & & 1 & $\mathbf{F}(11) 1400 \mathrm{~S} 12 \mathrm{~W} 07$ 1B & $\mathrm{L}$ & \\
\hline \multirow[t]{2}{*}{16} & $21 / 05$ & $\mathrm{Y}$ & $\mathrm{Y}$ & & & 1 & $\mathbf{F}(19) 2233$ N09 E20 1B & $\mathrm{L}$ & \\
\hline & 1974 & & & & & & & & \\
\hline 17 & $10 / 06$ & $\mathrm{~N}$ & $\mathrm{Y}$ & & & 1 & $\mathbf{F}(07) 0918 \mathrm{~S} 16 \mathrm{~W} 27$ 1B & & \\
\hline 18 & $04 / 07$ & $\mathrm{~N}$ & Y & & & 1 & $\mathbf{F}(01) 1556 \mathrm{~S} 13$ E24 1N & & \\
\hline 19 & $05 / 07$ & $\mathrm{~N}$ & $\mathrm{Y}$ & & & 1 & $\mathbf{F}(02) 2315 \mathrm{~S} 16 \mathrm{E} 121 \mathrm{~N}$ & & \\
\hline 20 & $06 / 07$ & $\mathrm{~N}$ & $\mathrm{Y}$ & & & 1 & $\mathbf{F}(04) 0634$ S15 W04 1B & & \\
\hline 21 & $15 / 09$ & & $\mathrm{Y}$ & & & 1 & $\mathbf{F}(13) 1513$ N14 E24 3B & & \\
\hline 22 & $12 / 10$ & $\mathrm{Y}$ & $\mathrm{Y}$ & & & 1 & $\mathbf{P}(10) \mathrm{S} 12271$ E24 & - & \\
\hline \multirow[t]{2}{*}{23} & $08 / 11$ & $\mathrm{~N}$ & $\mathrm{Y}$ & & & 1 & $\mathbf{F}(06) 1404$ N15 E14 1B & & \\
\hline & 1975 & & & & & & & & \\
\hline 24 & $06 / 01$ & Y & Y & & Y & 22 & $\mathbf{N}$ & - & \\
\hline 25 & $07 / 01$ & & $\mathrm{Y}$ & & & 1 & $\mathbf{F}(06) 0735$ N04 E20 1N & $\mathrm{N}$ & \\
\hline & 1976 & & & & & & & & \\
\hline 26 & $10 / 01$ & $\mathrm{Y}$ & $\mathrm{N}$ & & & 1 & $\mathbf{N}$ & - & $\mathrm{Y}$ \\
\hline & 1977 & & & & & & & & \\
\hline 27 & $29 / 07$ & & Y & & & 8 & $\mathbf{P}(26) \mathrm{N} 38175 \mathrm{C}$ & - & $\mathrm{Y}$ \\
\hline 28 & $12 / 09$ & $\mathrm{~N}$ & $\mathrm{Y}$ & & & 1 & $\mathbf{N}$ & - & Y \\
\hline 29 & $21 / 09$ & $\mathrm{Y}$ & $\mathrm{N}$ & & & 1 & $\mathbf{F}(18) 1028$ N07 W33 3B & & Y \\
\hline 30 & $11 / 10$ & $\mathrm{~N}$ & $\mathrm{Y}$ & & & 1 & $\mathbf{F}(08) 1217$ N06 E43 1N & & $\mathrm{N}$ \\
\hline 31 & $14 / 10$ & & $\mathrm{Y}$ & & & 1 & $\mathbf{F}(12) 0155$ N04 E02 & $\mathrm{N}$ & $\mathrm{Y}$ \\
\hline & & & & & & & $1 \mathrm{~N} / \mathbf{P}(15) \mathrm{N} 32190 \mathrm{C}$ & & \\
\hline 32 & $25 / 11$ & $\mathrm{Y}$ & $\mathrm{N}$ & & & 1 & $\mathbf{F}(22) 0945$ N23 W40 2B & $\mathrm{N}$ & $\mathrm{Y}$ \\
\hline 33 & $26 / 11$ & $\mathrm{~N}$ & $\mathrm{Y}$ & & & 1 & $\mathbf{N}$ & - & Y \\
\hline 34 & $30 / 11$ & & $\mathrm{Y}$ & & & 1 & $\mathbf{P}(26)$ N30 300 E30 & - & $\mathrm{Y}$ \\
\hline 35 & $02 / 12$ & & $\mathrm{Y}$ & & & 1 & $\mathbf{P}(30)$ N30 316 W32 & - & $\mathrm{Y}$ \\
\hline & 1978 & & & & & & & & \\
\hline 36 & $03 / 01$ & Y & Y & & & 5 & $\mathbf{F}(01) 2145$ S21 E06 2N & $\mathrm{N}$ & Y \\
\hline 37 & $05 / 01$ & & Y & & & 1 & $\mathbf{F}(03) 1015$ S15 E06 1B & $\mathrm{N}$ & Y \\
\hline 38 & $09 / 01$ & & Y & & & 1 & $\mathbf{P}(7) \mathrm{S} 18160 \mathrm{~W} 18$ & - & Y \\
\hline 39 & $28 / 01$ & $\mathrm{Y}$ & Y & & & 1 & $\mathbf{P}(26)$ N36 237 E03 & - & Y \\
\hline 40 & $01 / 03$ & $\mathrm{Y}$ & & & & 3 & $\mathbf{F}(25) 1449$ N19 W21 1B & $\mathrm{L}$ & Y \\
\hline 41 & $08 / 03$ & $\mathrm{~N}$ & Y & & & 1 & $\mathbf{F}(06) 1125$ N26 E20 2B & $\mathrm{N}$ & $\mathrm{N}$ \\
\hline 42 & $12 / 04$ & $\mathrm{~N}$ & Y & & & 1 & $\mathbf{F}(09) 1202 \mathrm{~N} 18 \mathrm{~W} 251 \mathrm{~N}$ & $\mathrm{~N}$ & Y \\
\hline 43 & $13 / 04$ & $\mathrm{~N}$ & Y & & & 1 & $\mathbf{P}(12) \mathrm{S} 101 \mathrm{E} 32$ & - & $\mathrm{Y}$ \\
\hline 44 & $18 / 04$ & & Y & & & 1 & $\mathbf{F}(14) 0020$ N18 E28 1N & $\mathrm{N}$ & Y \\
\hline 45 & $21 / 05$ & $\mathrm{~N}$ & Y & & & 2 & $\mathbf{P}(20) \mathrm{S} 34222 \mathrm{~W} 22$ & - & $\mathrm{N}$ \\
\hline 46 & $02 / 06$ & $\mathrm{~N}$ & $\mathrm{Y}$ & & & 1 & $\mathbf{F}(30) 0630 \mathrm{~N} 16 \mathrm{~W} 30$ 2B & $\mathrm{N}$ & $\mathrm{Y}$ \\
\hline 47 & $04 / 06$ & $\mathrm{Y}$ & & & & 21 & $\mathbf{F}(01) 2113$ N23 W45 1B & $\mathrm{N}$ & $\mathrm{Y}$ \\
\hline 48 & $03 / 07$ & & Y & & & 1 & $\mathbf{P}(01) \mathrm{N} 16315$ E20 & - & Y \\
\hline 49 & $13 / 07$ & $\mathrm{~N}$ & $\mathrm{Y}$ & & & 1 & $\mathbf{P}(12) \mathrm{N} 27226 \mathrm{C}$ & - & $\mathrm{Y}$ \\
\hline 50 & $18 / 08$ & $\mathrm{~N}$ & $\mathrm{Y}$ & & & 1 & $\mathbf{P}(16) \mathrm{S} 2477$ E20 & - & Y \\
\hline 51 & $27 / 08$ & $\mathrm{Y}$ & $\mathrm{N}$ & $\mathrm{Y}$ & & 4 & $\mathbf{P}(24)$ N50 316 E40 & - & Y \\
\hline 52 & $25 / 09$ & $\mathrm{~N}$ & $\mathrm{Y}$ & $\mathrm{N}$ & $\mathrm{N}$ & 4 & $\mathbf{F}(22) 2129 \mathrm{~S} 23 \mathrm{~W} 131 \mathrm{~N}$ & $\mathrm{~N}$ & Y \\
\hline 53 & $28 / 09$ & $\mathrm{Y}$ & Y & $\mathrm{Y}$ & & 1 & $\mathbf{F}(26) 2217$ N28 W07 1N & $\mathrm{N}$ & Y \\
\hline 54 & $29 / 09$ & $\mathrm{Y}$ & $\mathrm{Y}$ & $\mathrm{Y}$ & Y & 17 & $\mathbf{F}(27) 1428$ N27 W19 2B & $\mathrm{L}$ & Y \\
\hline
\end{tabular}


Table 1 (contd)

\begin{tabular}{|c|c|c|c|c|c|c|c|c|c|}
\hline \multicolumn{7}{|c|}{ IP signature } & \multicolumn{3}{|l|}{ Solar association } \\
\hline no. & date & $\mathrm{MC}$ & $\mathrm{A}(\mathrm{He})$ & BDE & BDI & ref. & $\mathrm{F} / \mathrm{P}$ & $\mathrm{X}$ & $\mathrm{CH}$ \\
\hline 55 & $09 / 10$ & $\mathrm{Y}$ & & & & 4 & $\mathbf{P}(7)$ N33 101 E30 & - & $\mathrm{Y}$ \\
\hline 56 & $17 / 10$ & $\mathrm{Y}$ & & & & 4 & $\mathbf{F}(13) 1233 \mathrm{~S} 18$ W01 2B & $\mathrm{N}$ & $\mathrm{Y}$ \\
\hline 57 & $12 / 11$ & $\mathrm{Y}$ & $\mathrm{Y}$ & $\mathrm{Y}$ & $\mathrm{Y}$ & 20 & $\begin{array}{l}\text { F(10) } 0048 \text { N17 E01 } \\
2 \mathrm{~N} / \mathbf{P}(10) \text { N24 } 19 \text { E20 }\end{array}$ & $\mathrm{S}$ & $\mathrm{Y}$ \\
\hline 58 & $\begin{array}{l}14 / 12 \\
\mathbf{1 9 7 9}\end{array}$ & $\mathrm{N}$ & $\mathrm{Y}$ & $\mathrm{N}$ & $\mathrm{N}$ & 25 & $\mathbf{F}(12) 0404 \mathrm{~S} 13$ E05 1N & $\mathrm{S}$ & $\mathrm{Y}$ \\
\hline 59 & $06 / 01$ & $\mathrm{Y}$ & $\mathrm{N}$ & & & 1 & $\mathbf{N}$ & - & $\mathrm{Y}$ \\
\hline 60 & $18 / 02$ & $\mathrm{~N}$ & & $\mathrm{Y}$ & $\mathrm{Y}$ & 19 & $\mathbf{P}(15)$ N45 187 E05 & - & $\mathrm{Y}$ \\
\hline 61 & $21 / 02$ & $\mathrm{Y}$ & $\mathrm{Y}$ & $\mathrm{Y}$ & & 4 & $\mathbf{F}(19) 1758$ N16 E02 2B & & $\mathrm{Y}$ \\
\hline 62 & $04 / 03$ & $\mathrm{~N}$ & & $\mathrm{~N}$ & $\mathrm{Y}$ & 20 & $\mathbf{P}(3) \mathrm{S} 3041 \mathrm{~W} 30$ & - & $\mathrm{Y}$ \\
\hline 63 & $09 / 03$ & $\mathrm{~N}$ & $\mathrm{Y}$ & $\mathrm{Y}$ & & 9 & $\mathbf{F}(05) 1409$ N12 E25 1B & $\mathrm{L}$ & $\mathrm{Y}$ \\
\hline 64 & $22 / 03$ & $\mathrm{Y}$ & $\mathrm{Y}$ & Y & & 4 & $\mathbf{F}(19) 1654$ N07 E15 1B & $\mathrm{L}$ & $\mathrm{Y}$ \\
\hline 65 & $01 / 04$ & $\mathrm{~N}$ & $\mathrm{Y}$ & $\mathrm{N}$ & & 25 & $\mathbf{N}$ & - & $\mathrm{N}$ \\
\hline 66 & $03 / 04$ & $\mathrm{Y}$ & $\mathrm{N}$ & $\mathrm{Y}$ & $\mathrm{Y}$ & 9 & $\mathbf{F}(31) 2315$ S24 E19 2B & $\mathrm{N}$ & $\mathrm{Y}$ \\
\hline 67 & $05 / 04$ & $\mathrm{~N}$ & $\mathrm{Y}$ & $\mathrm{Y}$ & $\mathrm{Y}$ & 20 & $\mathbf{F}(03) 0105 \mathrm{~S} 25 \mathrm{~W} 141 \mathrm{~B}$ & $\mathrm{~L}$ & $\mathrm{Y}$ \\
\hline 68 & $24 / 04$ & $\mathrm{Y}$ & $\mathrm{Y}$ & $\mathrm{Y}$ & $\mathrm{Y}$ & 6 & $\mathbf{P}(23) \mathrm{S} 1938 \mathrm{C}$ & - & $\mathrm{Y}$ \\
\hline 69 & $29 / 05$ & $\mathrm{~N}$ & $\mathrm{Y}$ & $\mathrm{Y}$ & $\mathrm{Y}$ & 17 & $\mathbf{P}(27)$ N15 360 W40 & - & $\mathrm{Y}$ \\
\hline 70 & $06 / 07$ & $\mathrm{~N}$ & & $\mathrm{~N}$ & $\mathrm{Y}$ & 20 & $\mathbf{F}(03) 2300 \mathrm{~N} 04 \mathrm{~W} 022 \mathrm{~N}$ & $\mathrm{~N}$ & $\mathrm{Y}$ \\
\hline 71 & $20 / 08$ & $\mathrm{~N}$ & & $\mathrm{~N}$ & $\mathrm{Y}$ & 20 & $\mathbf{P}(17) \mathrm{N} 21288$ E12 & - & $\mathrm{Y}$ \\
\hline 72 & $29 / 08$ & $\mathrm{~N}$ & $\mathrm{Y}$ & Y & $\mathrm{Y}$ & 20 & F(26) 1615 N05 W11 2B & $\mathrm{L}$ & $\mathrm{Y}$ \\
\hline 73 & $\begin{array}{l}06 / 10 \\
\mathbf{1 9 8 0}\end{array}$ & $\mathrm{Y}$ & $\mathrm{N}$ & $\mathrm{Y}$ & & 9 & $\mathbf{F}(04) 1048$ N11 E27 1N & $\mathrm{N}$ & \\
\hline 74 & $19 / 03$ & Y & & & $\mathrm{Y}$ & 24 & $\mathbf{F}(15) 0900 \mathrm{~S} 16 \mathrm{~W} 201 \mathrm{~F}$ & $\mathrm{~N}$ & $\mathrm{~N}$ \\
\hline 75 & $06 / 04$ & $\mathrm{~N}$ & & $\mathrm{Y}$ & $\mathrm{Y}$ & 20 & $\mathbf{P}(4)$ S25 $136 \mathrm{C}$ & - & $\mathrm{N}$ \\
\hline 76 & $11 / 06$ & $\mathrm{~N}$ & & & $\mathrm{Y}$ & 17 & $\mathrm{~F}(07) 0518 \mathrm{~S} 14 \mathrm{~W} 35$ 1B & $\mathrm{S}$ & $\mathrm{Y}$ \\
\hline 77 & $19 / 06$ & $\mathrm{Y}$ & & & & 7 & $\mathbf{F}(17) 0718 \mathrm{~S} 11 \mathrm{~W} 251 \mathrm{~N}$ & $\mathrm{~N}$ & $\mathrm{Y}$ \\
\hline 78 & $18 / 07$ & $\mathrm{~N}$ & & $\mathrm{Y}$ & $\mathrm{N}$ & 20 & $\mathbf{F}(14) 0818 \mathrm{~S} 17 \mathrm{E} 433 \mathrm{~N}$ & $\mathrm{~S}$ & Y \\
\hline 79 & $25 / 07$ & $\mathrm{Y}$ & & $\mathrm{Y}$ & $\mathrm{Y}$ & 20 & $\mathbf{F}(21) 2333 \mathrm{~S} 26 \mathrm{~W} 281 \mathrm{~N}$ & $\mathrm{~N}$ & $\mathrm{Y}$ \\
\hline 80 & $18 / 10$ & $\mathrm{~N}$ & & $\mathrm{Y}$ & $\mathrm{N}$ & 20 & $\mathbf{F}(14) 0629$ S08 W07 2B & $\mathrm{L}$ & $\mathrm{Y}$ \\
\hline 81 & $24 / 11$ & $\mathrm{~N}$ & & $\mathrm{Y}$ & $\mathrm{N}$ & 20 & $\mathbf{F}(23) 1752 \mathrm{~N} 11 \mathrm{~W} 23$ 1B & $\mathrm{L}$ & $\mathrm{Y}$ \\
\hline 82 & $26 / 11$ & $\mathrm{~N}$ & & $\mathrm{~N}$ & $\mathrm{Y}$ & 20 & F(24) 1346 N07 W24 1B & $\mathrm{S}$ & $\mathrm{Y}$ \\
\hline 83 & $\begin{array}{l}19 / 12 \\
1981\end{array}$ & $\mathrm{Y}$ & & $\mathrm{Y}$ & $\mathrm{Y}$ & 24 & F(16) 1427 N09 E14 1B & $\mathrm{L}$ & $\mathrm{Y}$ \\
\hline 84 & $06 / 02$ & $\mathrm{Y}$ & & Y & & 21 & $\mathbf{F}(03) 0549$ N23 E24 1F & $\mathrm{S}$ & $\mathrm{Y}$ \\
\hline 85 & $05 / 03$ & $\mathrm{Y}$ & & $\mathrm{Y}$ & & 21 & $\mathbf{F}(02) 2112 \mathrm{~S} 17 \mathrm{~W} 341 \mathrm{~N}$ & $\mathrm{~S}$ & $\mathrm{Y}$ \\
\hline 86 & $26 / 04$ & $\mathrm{~N}$ & & $\mathrm{~N}$ & $\mathrm{Y}$ & 20 & $\mathbf{P}(24) \mathrm{S} 19110 \mathrm{C}$ & - & $\mathrm{Y}$ \\
\hline 87 & $10 / 05$ & $\mathrm{~N}$ & & $\mathrm{Y}$ & $\mathrm{N}$ & 20 & $\mathbf{F}(07) 1739$ N08 W31 1B & $\mathrm{S}$ & $\mathrm{Y}$ \\
\hline 88 & $14 / 05$ & $\mathrm{~N}$ & & $\mathrm{Y}$ & $\mathrm{Y}$ & 20 & $\mathbf{P}(11)$ N29 $265 \mathrm{~W} 18$ & - & Y \\
\hline 89 & $16 / 05$ & $\mathrm{~N}$ & & $\mathrm{~N}$ & $\mathrm{Y}$ & 20 & $\mathbf{F}(14) 0808$ N20 E32 3B & $\mathrm{L}$ & $\mathrm{N}$ \\
\hline 90 & $17 / 05$ & $\mathrm{Y}$ & & $\mathrm{Y}$ & $\mathrm{Y}$ & 20 & $\mathbf{F}(15) 2354$ N13 E14 1N & $\mathrm{N}$ & $\mathrm{N}$ \\
\hline 91 & $10 / 08$ & $\mathrm{~N}$ & & $\mathrm{Y}$ & $\mathrm{N}$ & 20 & $\mathbf{P}(7) \mathrm{S} 16147 \mathrm{C}$ & - & $\mathrm{N}$ \\
\hline 92 & $23 / 08$ & $\mathrm{~N}$ & & $\mathrm{~N}$ & $\mathrm{Y}$ & 20 & $\mathbf{F}(20) 1811 \mathrm{~S} 16 \mathrm{E} 11$ 1B & $\mathrm{N}$ & $\mathrm{Y}$ \\
\hline 93 & $10 / 10$ & $\mathrm{~N}$ & & $\mathrm{Y}$ & $\mathrm{N}$ & 20 & $\mathbf{P}(8)$ S21 6 E40 & - & $\mathrm{N}$ \\
\hline 94 & $11 / 11$ & & & $\mathrm{Y}$ & $\mathrm{Y}$ & 20 & $\mathbf{F}(08) 0358$ S20 E27 1B & $\mathrm{L}$ & $\mathrm{N}$ \\
\hline 95 & $25 / 11$ & $\mathrm{~N}$ & & $\mathrm{Y}$ & $\mathrm{Y}$ & 20 & $\mathbf{F}(22) 0730 \mathrm{~N} 13 \mathrm{~W} 19$ 1B & $\mathrm{L}$ & $\mathrm{Y}$ \\
\hline 96 & $12 / 12$ & $\mathrm{~N}$ & & $\mathrm{Y}$ & $\mathrm{N}$ & 20 & $\mathbf{F}(09) 0333 \mathrm{~N} 20 \mathrm{~W} 052 \mathrm{~N}$ & $\mathrm{~L}$ & $\mathrm{~N}$ \\
\hline 97 & $\begin{array}{l}29 / 12 \\
1982\end{array}$ & $\mathrm{~N}$ & & $\mathrm{Y}$ & $\mathrm{Y}$ & 20 & $\mathbf{F}(27) 0158$ S13 E17 1N & $\mathrm{L}$ & $\mathrm{Y}$ \\
\hline 98 & $31 / 01$ & Y & & & $\mathrm{Y}$ & 13,17 & $\mathbf{F}(29) 0220$ S14 E39 1B & $\mathrm{L}$ & $\mathrm{Y}$ \\
\hline 99 & $01 / 02$ & $\mathrm{~N}$ & & $\mathrm{Y}$ & $\mathrm{N}$ & 20 & $\mathbf{F}(31) 0020 \mathrm{~S} 13 \mathrm{E} 082 \mathrm{~N}$ & $\mathrm{~L}$ & $\mathrm{Y}$ \\
\hline 100 & $03 / 02$ & $\mathrm{~N}$ & & $\mathrm{Y}$ & $\mathrm{Y}$ & 20 & $\mathbf{F}(01) 1350 \mathrm{~S} 16 \mathrm{~W} 103 \mathrm{~B}$ & $\mathrm{~L}$ & $\mathrm{Y}$ \\
\hline 101 & $11 / 02$ & $\mathrm{Y}$ & & & $\mathrm{Y}$ & 13,17 & $\mathbf{F}(09) 0336 \mathrm{~S} 12 \mathrm{E} 042 \mathrm{~N}$ & $\mathrm{~L}$ & $\mathrm{Y}$ \\
\hline 102 & $11 / 07$ & $\mathrm{~N}$ & & $\mathrm{Y}$ & $\mathrm{N}$ & 20 & $\mathbf{N}$ & - & Y \\
\hline 103 & $13 / 07$ & $\mathrm{~N}$ & & $\mathrm{Y}$ & $\mathrm{Y}$ & 20 & $\mathbf{F}(10) 2210 \mathrm{~S} 19 \mathrm{~W} 151 \mathrm{~N}$ & $\mathrm{~L}$ & $\mathrm{Y}$ \\
\hline 104 & $05 / 09$ & & & $\mathrm{Y}$ & $\mathrm{Y}$ & 20 & $\mathbf{F}(03) 2344$ N10 E36 2B & $\mathrm{L}$ & $\mathrm{Y}$ \\
\hline 105 & $21 / 09$ & $\mathrm{~N}$ & & $\mathrm{Y}$ & $\mathrm{Y}$ & 20 & $\mathbf{F}(19) 1351 \mathrm{~S} 12 \mathrm{E} 022 \mathrm{~N}$ & $\mathrm{~L}$ & $\mathrm{Y}$ \\
\hline 106 & $25 / 09$ & $\mathrm{Y}$ & & & & 21 & $\mathbf{P}(24)$ N09 90 E10 & - & $\mathrm{Y}$ \\
\hline 107 & $23 / 11$ & $\mathrm{Y}$ & & & & 14 & $\mathbf{F}(20) 1808$ S11 W09 2B & $\mathrm{L}$ & $\mathrm{Y}$ \\
\hline & 1984 & & & & & & & & \\
\hline 108 & $17 / 02$ & $\mathrm{Y}$ & & & & 16 & $\mathbf{F}(16) 0224 \mathrm{~S} 16 \mathrm{~W} 49$ 1N & $\mathrm{S}$ & $\mathrm{Y}$ \\
\hline
\end{tabular}

[1] Borrini et al. (1982a); [2] Borrini et al. (1982b); [3] Bothmer and Schwenn (1992); [4] Bravo and Lanzagorta (1994); [5] Burlaga et al. (1981); [6] Burlaga (1987); [7] Burlaga (1991); [8] Gosling et al. (1980); [9] Gosling et al. (1987); [10] Gosling et al. (1990); [11] Gosling (1990); [12] Hirshberg et al. (1970); [13] Kahler and Reames (1991); [14] Kallenrode et al. (1993); [15] Klein and Bur- laga (1982); [16] Lindsay et al. (1995); [17] Marsden et al. (1987); [18] Marubashi (1986); [19] McComas et al. (1989); [20] Richardson and Cane (1993); [21] Rust (1994); [22] Webb et al. (1993); [23] Wilson and Hildner (1986); [24] Zhang and Burlaga (1988); [25] Zwickl et al. (1983) 
disturbances was related to some kind of coronal hole transients, where coronal holes suddenly change their size and/or shape. The combined results of the Solwind/ Helios and IPS studies indicate that the occurrence of a CME and a coronal hole transient are always involved in the generation of major interplanetary disturbances. We have presented a solar scenario in which the emergence of new photospheric magnetic flux produces both the ejection of mass from a coronal helmet and the expansion of a nearby coronal hole (Bravo, 1995). Although it seems to be well established that flares and prominence eruptions do not play a role in the formation of IP shocks, it is not clear if some kind of flare or prominence ejecta can reach the interplanetary medium at the moment of the generation of a major solar event and whether or not they contribute to the structure of the IP disturbance.

Approximately half of the major transient IP disturbances are characterized by the presence of a shock wave moving radially outwards from the Sun (Gosling et al., 1987), but not all the shocks are followed by plasma bodies with the particular signatures of a transiently ejected solar material that can be considered to constitute the "piston" driving the shock. Sheeley et al. (1985) reported a plasma with the "typical signature of a driver gas" only behind $46 \%$ of the Helios shocks. In the IPS study period we also looked for the events where a plasma cloud (a region of enhanced density) and/or magnetic cloud was present behind a transient shock according to satellite observations, and found such clouds only in $40 \%$ of the cases (Bravo and Lanzagorta, 1994). This has been explained by arguing that the angular extension of the shock is much wider than that of the associated piston (Borrini et al., 1982a; Richardson and Cane, 1993). However, an interesting characteristic of the Helios/Solwind and IPS piston cases is that all of them corresponded to solar events with a flare, and in the IPS cases also with the eruption of a prominence, occurring at the solar source. That is, no "piston" was found in the IP disturbances when no flare or prominence eruption occurred. Moreover, in the IPS study we could also determine that in all the piston cases the nearsurface explosive event happened near the solar central meridian. This suggests that flares and prominence eruptions may contribute also to the structure of the IP transient, imprinting on the solar wind some of the socalled "piston" characteristics. In particular, some magnetic clouds have been associated with flares (e.g. Burlaga et al., 1981, Burlaga, 1987) and others with prominence eruptions (e.g. Burlaga et al., 1982; Wilson and Hildner, 1986; Tang et al., 1989, Bothmer and Schwenn, 1997; Bothmer and Rust, 1997). Helium enhancements in the solar wind have been associated with flares (e.g. Hirshberg, 1972). In this paper we took a set of 108 IP events taken from the literature where different transient signatures (magnetic clouds, helium enrichments and bidirectional electrons and ions) were observed in the solar wind behind shocks in the ecliptic plane at $\sim 1 \mathrm{AU}$ to study the different combinations of signatures in each IP transient event, and look for their possible association with near-surface solar eruptive events.

\section{The interplanetary signatures}

Under the assumption that the obvious signatures of IP transients mentioned are caused by coronal mass ejections, some authors are using the terms $C M E$ or $C M E$ interplanetary counterpart to address the ejected material which they identify in the interplanetary medium by a variety of plasma and magnetic signatures. These include: density changes, ion and electron temperature depressions, helium abundance enhancements, bidirectional halo electrons, bidirectional ions, low plasma beta, strong magnetic field, low magnetic field strength variance, anomalous field rotation and unusual ionization states (e.g. Gosling, 1993). It is probable that such a variety of signatures does not correspond to just one kind of solar ejected material and to just one type of solar eruption. In this paper we shall use the generic name of ejecta to address any solar wind parcels with unusual characteristics that are the result of a solar mass ejection (SME), implying with this term (following Schwenn, 1996; Bothmer and Schwenn, 1997) any transient plasma ejection from the Sun. Then, solar mass ejections can be CMEs, but SMEs also include the ejection of plasma from the eruption of a prominence, a flare, or a coronal hole transient. We have selected four particular signatures of the ejecta behind shocks observed in the ecliptic at $1 \mathrm{AU}$ to find the particular SME that originated them. These signatures are the following:

Magnetic clouds (MC): Interplanetary ejecta with the following properties: (1) the magnetic field strength is higher than average $(B \geq 8 \mathrm{nT}) ;(2)$ the magnetic field direction rotates smoothly through a large angle during an interval of the order of a day; (3) the proton temperature is lower than average (Burlaga, 1991).

Helium enhancements $[\mathrm{A}(\mathrm{He})]$ : Plasma with a ratio $\mathrm{He}^{++} / \mathrm{H}^{+}>0.08$ (Borrini et al., 1982a).

Bidirectional streamings of electrons (BDE): Bidirectional fluxes of electrons with energy $\geq 50 \mathrm{eV}$ (Gosling et al., 1987).

Bidirectional streamings of ions: (BDI) Bidirectional fluxes of ions with energy $<20 \mathrm{keV}$ ) (Marsden et al., 1987).

\section{The data base}

We have taken from the literature a total of 108 transient IP events where the presence of a magnetic cloud, a helium enhancement and/or a bidirectional streaming of electrons or ions is reported behind a transient interplanetary shock (see references at the bottom of Table 1). When necessary, we completed the solar wind information using the data in the OMNI tape, which contains interplanetary plasma and magnetic field data from several American and Russian spacecraft maintained and updated by the National Space Science Data Center. Our set of IP events was formed without any selection criteria, just collecting as much as we could find, but the final representation of signatures was more or less even. Our set comprises 40 
magnetic clouds, 55 helium rich ejecta, $37 \mathrm{BDE}$ events and 32 BDI events, which, of course, are not independent. To look for their solar association, the $\mathrm{H} \alpha$ flare as well as the X-ray information was taken from the Solar Geophysical Data, and the disappearing filaments were found in the Meudon Observatory reports. The information for coronal holes was obtained from the Solar Geophysical Data and from the catalogue of Stewart et al. (1985).

The list of the studied IP events is presented in Table 1. The first column gives the event number; the second column is the date of observation of the IP signatures at $1 \mathrm{AU}$; columns three to six indicate whether or not a particular IP signature appears (blanks indicate lack of data); the seventh column gives the number of the reference where each event was reported according to the block of references below the table.

\section{The association between interplanetary signatures}

We first study the association between the individual signatures of interplanetary transients. The results are shown in Table 2, where each percentage was taken with respect to the subset for which all the relevant information was available. We found that in our sample, clouds always appeared in association with both BDEs and BDIs, while the opposite is not so: about $60 \%$ of bidirectional fluxes were not associated with a cloud. This is in accordance with the results of Gosling (1990, 1993), who states that only about $1 / 3$ of BDE events are associated with magnetic clouds. Most of the $\mathrm{A}(\mathrm{He})$ events in our sample appeared in events without cloud, while they showed a high percentage of association with both kinds of bidirectional events. When the bidirectional information is complete, we found that in $\mathrm{A}(\mathrm{He})$ events both BDEs and BDIs were present or both were absent. On the other hand, the association of BDI events with helium enrichments was $86 \%$, while less than $80 \%$ of the BDEs were associated with $\mathrm{A}(\mathrm{He}) \mathrm{s}$. It is also important to notice that both types of bidirectional streamings were not always observed together: only $\sim 70 \%$ of the events showing one of the bidirectional signatures showed also the other. Only two of our events showed clearly just one signature behind the shock (events 52 and 58). Both corresponded to helium enrichments where cloud and bidirectional streamings were reported to be absent. It is important to mention that due to the way in which our data base was constructed, the obtained percentages of association (here and in all other sections) are not really representative of any particular period, and they can be biased by the fact that only positive findings are usually

Table 2. Association between IP signatures

\begin{tabular}{llcc}
\hline $\mathrm{MC}$ & $72 \% \mathrm{~A}(\mathrm{He})$ & $100 \% \mathrm{BDE}$ & $100 \% \mathrm{BDI}$ \\
$\mathrm{A}(\mathrm{He})$ & $32 \% \mathrm{MC}$ & $77 \% \mathrm{BDE}$ & $78 \% \mathrm{BDI}$ \\
$\mathrm{BDE}$ & $40 \% \mathrm{MC}$ & $77 \% \mathrm{~A}(\mathrm{He})$ & $69 \% \mathrm{BDI}$ \\
$\mathrm{BDI}$ & $37 \% \mathrm{MC}$ & $86 \% \mathrm{~A}(\mathrm{He})$ & $74 \% \mathrm{BDE}$ \\
\hline
\end{tabular}

reported in the literature. In particular, we only have two cases where BDEs and BDIs were reported to be absent.

When computing the delays between the arrival of the shock at Earth and the arrival of the ejecta, we found that they varied from 0 to $30 \mathrm{~h}$ for clouds, from 2 to less than $48 \mathrm{~h}$ for $\mathrm{A}(\mathrm{He}) \mathrm{s}$, from 0 to $24 \mathrm{~h}$ for BDEs, and from 0 to $37 \mathrm{~h}$ for BDIs. The delays of $\mathrm{A}(\mathrm{He}) \mathrm{s}$ were obtained from Borrini et al. (1982a,b) and in many occasions it is only mentioned that they appear within $48 \mathrm{~h}$ after the associated shock. BDE and BDI delays were obtained from Gosling et al. (1987), Kahler and Reames (1991) and Marsden et al. (1987).

\section{Overlapping of IP signatures}

We have the starting time and duration of all the signatures in only a few cases, but this sample was sufficient to see that the different signatures can be arranged in various ways within the ejecta. Table 3 shows the initial and final times of observation of each signature to illustrate the different observed arrangements. One or two asterisks indicate that the final time corresponds to one or two days after the initial time. In most of the events we found that clouds and BDEs overlap (e.g. events 66, 83 and 84), but sometimes BDEs finish before the cloud's arrival (e.g. event 51). In the few cases in our sample when the time of observation is known, BDIs were never observed before the cloud, most of the times were found within it (e.g. events 66, 74, $90,101)$, but they sometimes appeared after the cloud passing (e.g. event 83 ). In the cases of clouds and helium enrichments where we have the time for the $\mathrm{A}(\mathrm{He})$ event, we found that $\mathrm{A}(\mathrm{He}) \mathrm{s}$ were always inside the cloud (e.g. events 36, 61 and 68). When we could determine possible overlappings of helium events and bidirectional fluxes they did not show any systematic temporal relation (see events 61 and 68). When BDEs and BDIs were present in the same event, BDIs appeared after the BDE starting time (e.g. events 66,83 and 90). Of course, many other combinations may be possible, although not observed in our very small sample.

Table 3. Time of observation of different signatures

\begin{tabular}{|c|c|c|c|c|}
\hline no. & $\begin{array}{l}\text { time } \\
\text { MC }\end{array}$ & $\mathrm{A}(\mathrm{He})$ & BDE & BDI \\
\hline 25 & 00:00-20:40 & & & $11: 00-15: 00$ \\
\hline 37 & $10: 00-20: 00^{*}$ & 13:00-17:00 & & \\
\hline 52 & $17: 00-14: 00^{*}$ & & $08: 00-12: 00$ & \\
\hline 62 & $04: 00-04: 00 *$ & $16: 00-01: 00^{*}$ & $15: 00-16: 30$ & \\
\hline 67 & $19: 00-01: 00^{* *}$ & & $\begin{array}{l}19: 30-20: 20 \\
21: 20-01: 00^{* *}\end{array}$ & $16: 00^{*}-24: 00^{*}$ \\
\hline 69 & 09:00-16:00* & 09:00-16:00 & $11: 10-23: 10$ & \\
\hline 74 & $15: 00-04: 00 *$ & & $02: 00^{*}-12: 00^{*}$ & \\
\hline 75 & $15: 00-18: 00^{* *}$ & & & $21: 00-01: 00^{*}$ \\
\hline 84 & $14: 00-13: 00 *$ & & $13: 00-05: 00 *$ & $20: 00^{*}-23: 00^{*}$ \\
\hline 85 & 19:00-09:00* & & 18:00-09:00* & \\
\hline 91 & $07: 00-22: 00$ & & $08: 00-14: 00^{*}$ & $12: 00-18: 00$ \\
\hline 102 & $20: 00-21: 00^{* *}$ & & & $00: 00^{*}-06.00^{* *}$ \\
\hline
\end{tabular}




\section{The solar association}

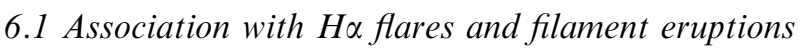

We looked for the possible association of each one of the 108 IP transient events in our sample with $\mathrm{H} \alpha$ flares of importance 1 or greater $(\mathrm{F})$ or disappearing filaments (P) by looking for Fs or Ps that happened within a window of $45^{\circ}$ (east or west) of the solar central meridian and in an adequate time to be associated with the IP signature observed at 1 AU. As no tracking of the IP disturbance from its solar source to 1 AU was made, the actual association between the solar and the IP events cannot be assured. To estimate the time of occurrence of the solar event responsible for the IP disturbance, we used the speed of the shock at 1 AU, calculated assuming it to be perpendicular to the solar wind flow. The solar events associated with each of the IP events are also listed in Table 1 . The eighth column gives the day and time of occurrence, position and importance of the associated $\mathrm{H} \alpha$ flare $(\mathrm{F})$, or the first day when an associated eruptive filament $(\mathrm{P})$ was no longer observed, as well as its position and its distance to the solar central meridian; a $\mathrm{C}$ indicates that the filament erupted while crossing central meridian. In this column, an $\mathrm{N}$ indicates that no $\mathrm{F}$ or $\mathrm{P}$ occurred in association with the IP event. For events 27 and 69, the associated filament was obtained from Harvey and Sheeley (1979) and from Cane et al. (1991), respectively.

We find that a very high percentage of our sample of IP events (94\%) was associated with $\mathrm{F}$ and/or $\mathrm{P}$ within the window: $62 \%$ with Fs, $28 \%$ with Ps, and $4 \%$ with an event where both an $\mathrm{F}$ and a $\mathrm{P}$ occurred together. The other $6 \%$ were seven events; in five of these a flare happened at an adequate time but out of our $45^{\circ}$ window, and for the other two no F or $\mathrm{P}$ was reported to take place at the right times. The selection of a window of $45^{\circ}$ is rather arbitrary, but the small number of IP events that could be associated with a flare outside the window shows that to consider the whole solar disk would not significantly change the foregoing percentages of association.

Table 4 shows the association of each type of IP signature with an F or P. Although all of them appeared in association with both types of solar activity, it is clear that they appeared more frequently in association with flares than with filament eruptions, the highest association with flares corresponding to BDEs and the lowest to $\mathrm{A}(\mathrm{He}) \mathrm{s}$. The highest association with filaments corresponded to $\mathrm{A}(\mathrm{He})$ events and the lowest to clouds. BDEs and BDIs had the lowest occurrence in absence of surface solar activity within our window. Combinations

Table 4. The solar association of IP signatures

\begin{tabular}{lllll}
\hline & F & P & FP & NO \\
\hline MC & $71 \%$ & $17 \%$ & $5 \%$ & $7 \%$ \\
A(He) & $55 \%$ & $33 \%$ & $5 \%$ & $7 \%$ \\
BDE & $73 \%$ & $22 \%$ & $3 \%$ & $2 \%$ \\
BDI & $69 \%$ & $25 \%$ & $3 \%$ & $3 \%$ \\
\hline
\end{tabular}

Table 5. Time-delays

\begin{tabular}{llllll}
\hline & & $1-2$ days & $2-3$ days & $3-4$ days & $4-5$ days \\
\hline MC & $\mathrm{F}$ & $35 \%$ & $41 \%$ & $24 \%$ & $0 \%$ \\
& $\mathrm{P}$ & $14 \%$ & $72 \%$ & $14 \%$ & $0 \%$ \\
$\mathrm{~A}(\mathrm{He})$ & $\mathrm{F}$ & $37 \%$ & $43 \%$ & $20 \%$ & $0 \%$ \\
& $\mathrm{P}$ & $17 \%$ & $67 \%$ & $11 \%$ & $5 \%$ \\
$\mathrm{BDE}$ & $\mathrm{F}$ & $37 \%$ & $37 \%$ & $22 \%$ & $4 \%$ \\
& $\mathrm{P}$ & $0 \%$ & $38 \%$ & $62 \%$ & $0 \%$ \\
$\mathrm{BDI}$ & $\mathrm{F}$ & $32 \%$ & $50 \%$ & $18 \%$ & $0 \%$ \\
& $\mathrm{P}$ & $0 \%$ & $50 \%$ & $50 \%$ & $0 \%$ \\
\hline
\end{tabular}

of signatures also appeared more frequently associated with flares. About $90 \%$ of the cases of bidirectional streamings with cloud were associated with $\mathrm{H} \alpha$ flares; $\sim 75 \%$ of the cases with cloud and helium were associated with flares.

Table 5 shows the time-intervals in days of the solar association of each signature for flares $(F)$ and filament eruptions $(\mathrm{P})$. The column labelled 1-2 days corresponds to delays between 24 and $48 \mathrm{~h}, 2-3$ is between 49 and 72 h, 3-4 means between 73 and $96 \mathrm{~h}$ and 4-5 from 97 to $120 \mathrm{~h}$. In no case was the solar-associated event observed less than 1 day before the arrival of the disturbance at $1 \mathrm{AU}$. The majority of magnetic clouds and helium enhancements associated with filaments were observed at $1 \mathrm{AU}$ between 2 and 3 days after the solar event. The majority of BDEs associated with filaments were observed between 3 and 4 days after the solar event, while BDIs were equally associated with solar events occurring between 2 and 3 days and 3 and 4 days. When the IP disturbances were associated with flares, delays were more evenly distributed in all timeintervals for all signatures. Very few IP events were associated with solar activity occurring between 4 and 5 days before.

\subsection{Association with $X$-ray events}

In the cases when an $\mathrm{H} \alpha$ flare was associated, we looked for the presence of X-ray fluxes of short (SDE) and long (LDE) duration in the Explorer and GOES records in the Solar Geophysical Data reports. An X-ray event was considered to be short when its duration was less than $2 \mathrm{~h}$, and long otherwise. This classification is based on the fact that X-ray events with durations exceeding $2 \mathrm{~h}$ are nearly always associated with CMES (Webb and Hundhausen, 1987). For shorter times, the proportion of associated events decreases, although no shortlifetime cut-off exists (Sheeley et al., 1983). The ninth column in Table 1 indicates whether a short (S) or long (L) duration X-ray event or no X-ray event $(\mathrm{N})$ was associated. The symbol "-" corresponds to the cases where no $\mathrm{H} \alpha$ flare could be associated. An association between $\mathrm{H} \alpha$ and X-ray flares was found in $66 \%$ of the cases, $43 \%$ with LDE and $23 \%$ with SDE. Table 6 shows the association between each particular signature and X-ray events. We see that the highest association corresponded to BDEs $(82 \%)$ and the lowest to $\mathrm{A}(\mathrm{He}) \mathrm{s}$ 
Table 6. The X-ray association of IP signatures

\begin{tabular}{llll}
\hline & SDE & LDE & NO \\
\hline MC & $25 \%$ & $36 \%$ & $39 \%$ \\
A(He) & $20 \%$ & $40 \%$ & $40 \%$ \\
BDE & $18 \%$ & $64 \%$ & $18 \%$ \\
BDI & $13 \%$ & $61 \%$ & $26 \%$ \\
\hline
\end{tabular}

Table 7. Time-delays for X-ray events

\begin{tabular}{lllccc}
\hline & & $1-2$ days & $2-3$ days & $3-4$ days & $4-5$ days \\
\hline \multirow{2}{*}{ MC } & SDE & $28 \%$ & $43 \%$ & $29 \%$ & $0 \%$ \\
& LDE & $40 \%$ & $60 \%$ & $0 \%$ & $0 \%$ \\
\multirow{3}{*}{ B(He) } & SDE & $60 \%$ & $20 \%$ & $20 \%$ & $0 \%$ \\
& LDE & $30 \%$ & $60 \%$ & $10 \%$ & $0 \%$ \\
\multirow{2}{*}{ BDI } & SDE & $20 \%$ & $20 \%$ & $40 \%$ & $20 \%$ \\
& LDE & $35 \%$ & $47 \%$ & $18 \%$ & $0 \%$ \\
& SDE & $67 \%$ & $0 \%$ & $33 \%$ & $0 \%$ \\
& LDE & $36 \%$ & $57 \%$ & $7 \%$ & $0 \%$
\end{tabular}

and clouds $(\sim 60 \%)$. All signatures were more associated with long-duration X-ray events than with shortduration events.

Table 7 shows the time between the appearance of each signature at $1 \mathrm{AU}$ and their associated X-ray events. For clouds, the delays were more or less evenly distributed between 1 and 4 days for SDE with a slight preference for values between 2 and 3 days. When associated with LDEs, all clouds arrive at Earth in less than 3 days and the majority after 2 days. $\mathrm{A}(\mathrm{He})$ events associated with SDE arrived at Earth more frequently between 1 and 2 days after the solar event, while the majority of those associated with LDEs arrived between 2 and 3 days. BDEs associated with SDE can arrive at Earth between 1 and 5 days after the solar event, with some preference between 3 and 4 days. Most of the BDEs associated with LDEs arrived at Earth before 3 days. BDIs associated with SDEs are more frequently observed between 1 and 2 days after the solar event, while those associated with LDEs arrived between 2 and 3 days after the solar event. In the cases where the IP signatures were related to an LDE event, they arrived at 1 AU mostly between 2 and 3 days after the solar event, very rarely after 3 days, and never after 4 days.

\subsection{Association with coronal holes}

We also looked for the presence of low-latitude coronal holes as recorded on the $\mathrm{He} 10830 \AA$ maps that were adjacent to the site of the flare or the eruptive filament associated with the interplanetary signatures. No coronal hole information was available before June 1975, and after that there were some gaps in the data. The last column on Table 1 indicates whether or not a coronal hole was present near the site of the solar event. For $75 \%$ of the cases in our study we had the coronal hole maps and found that in $85 \%$ of such cases a hole was beside the region of the explosive solar event. Figure 1 shows the position on Carrington rotation maps of the different solar structures (coronal holes, active regions and filaments) for some of the events. The percentage of association with coronal holes for each signature was: $93 \%$ for clouds, $88 \%$ for $\mathrm{A}(\mathrm{He}) \mathrm{s}, 83 \%$ for BDEs, and $84 \%$ for BDIs.

\section{Longitudinal distribution of the associated solar events}

We also studied the longitudinal distribution of the solar events associated with each particular IP signature, with respect to the solar central meridian, and the results are shown in Fig. 2. In the case of filaments we took the distance to the part of the filament nearest to the position of the solar central meridian at the time of the eruption. This time was considered to be midnight after the last day of observation of the filament, which gives an uncertainty of about $\pm 5^{\circ}$ in the location of the central meridian; the thin black column at $0^{\circ}$ represents the number of cases when the filament was crossing the central meridian at the time of eruption. We see from the figure that the majority of the solar-associated events were in a band of $30^{\circ}$ east or west of the solar central meridian: $80 \%$ for magnetic clouds, $91 \%$ for the helium enrichments, $81 \%$ for BDEs, and $84 \%$ for BDI. But we also notice that the distributions were not symmetric in all cases. Magnetic clouds were more associated with flares occurring on the west and filament eruptions occurring on the east. $\mathrm{A}(\mathrm{He})$ events do not seem to have a particular preference for flares on one hemisphere, but were clearly more associated with filament eruptions on the east. BDEs and BDIs showed no particular preference to be associated with flares or filament eruptions on a given hemisphere.

\section{Discussion and conclusions}

Solwind/Helios and IPS studies have shown that less than $50 \%$ of transient interplanetary shocks are associated with near-surface solar explosive events, that is $\mathrm{H} \alpha$ flares or eruptive filaments. In this paper the results obtained give this percentage to be much higher, $94 \%$, when we consider only those IP shocks showing behind particular signatures of solar ejecta (magnetic clouds, helium enhancements and bidirectional fluxes of suprathermal electrons or ions). These findings support the suggestion arisen from the Solwind/Helios and IPS studies that these kinds of IP signature correspond in most of the cases to coronal mass ejections accompanied by flares or filament eruptions. We also obtained that most of the IP signatures are associated with a nearsurface solar event $\pm 30^{\circ}$ from the solar central meridian, which suggests that most of these ejecta have an angular extension of $\leq 60^{\circ}$. The great variety of time-delays of the ejecta observed behind shocks at $1 \mathrm{AU}$, from 1 to $48 \mathrm{~h}$, makes it hard to consider that they always correspond to the shock's driver.

In this study we also found that, although commonly different signatures appear in a single interplanetary 

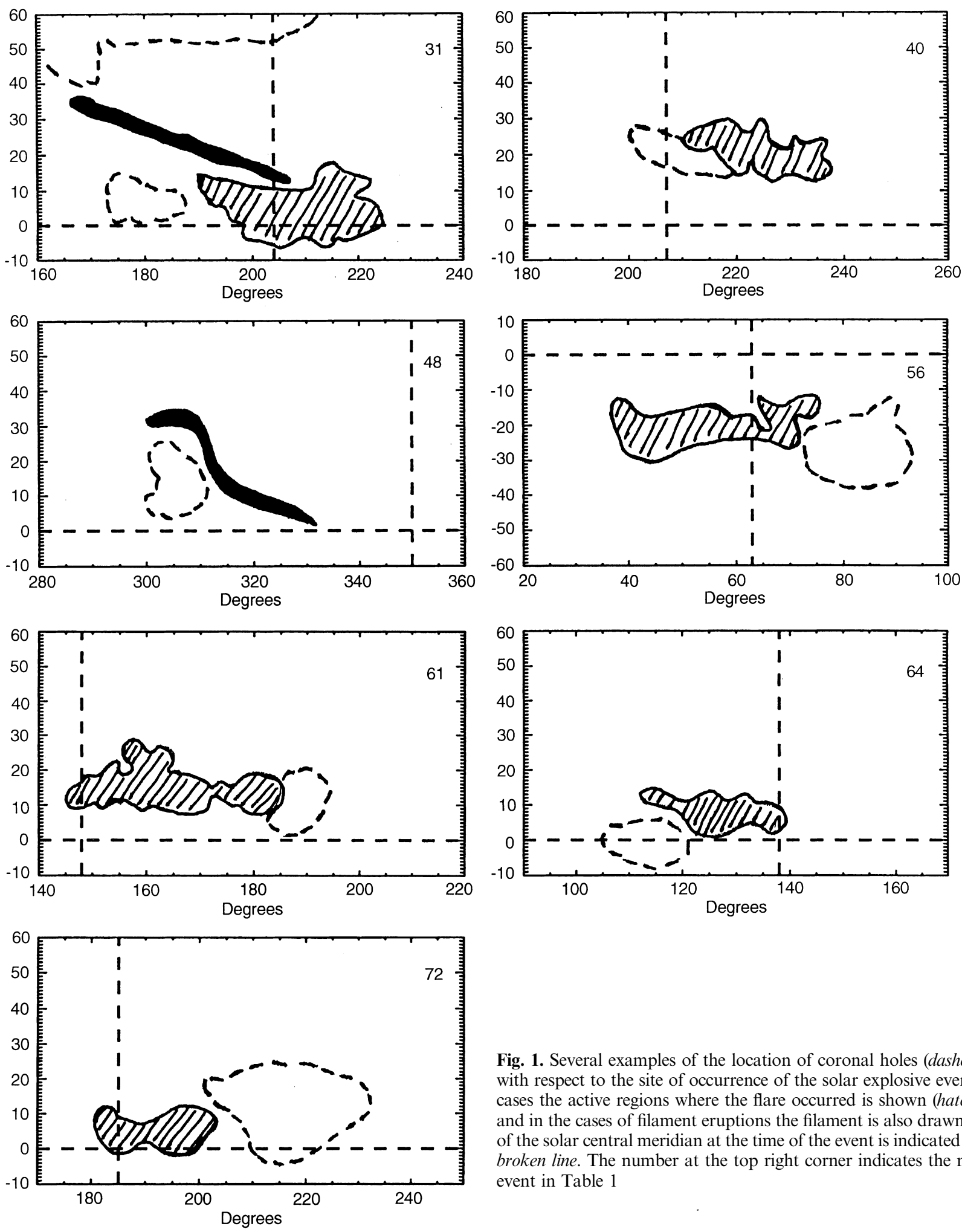

Fig. 1. Several examples of the location of coronal holes (dashed contours) with respect to the site of occurrence of the solar explosive event. In the flare cases the active regions where the flare occurred is shown (hatched regions), and in the cases of filament eruptions the filament is also drawn. The position of the solar central meridian at the time of the event is indicated with a vertical broken line. The number at the top right corner indicates the number of the event in Table 1

transient event, they are not necessarily observed simultaneously. That is, the ejecta is not a magnetic cloud carrying inside bidirectional streamings of electrons and ions and alpha particles. In many occasions the different signatures belong to different plasma regions within the ejecta. Most BDEs and BDIs were not associated with magnetic clouds, and when associ- ated, they were not necessarily inside the cloud, but may be found before or after the cloud. Richardson and Cane (1993) also found BDEs and BDIs outside the ejecta and Hammond et al. (1996) have reported the same situation for some BDI events observed by Ulysses. Helium enrichments when associated with a cloud seem to be always inside the cloud, but occupy 

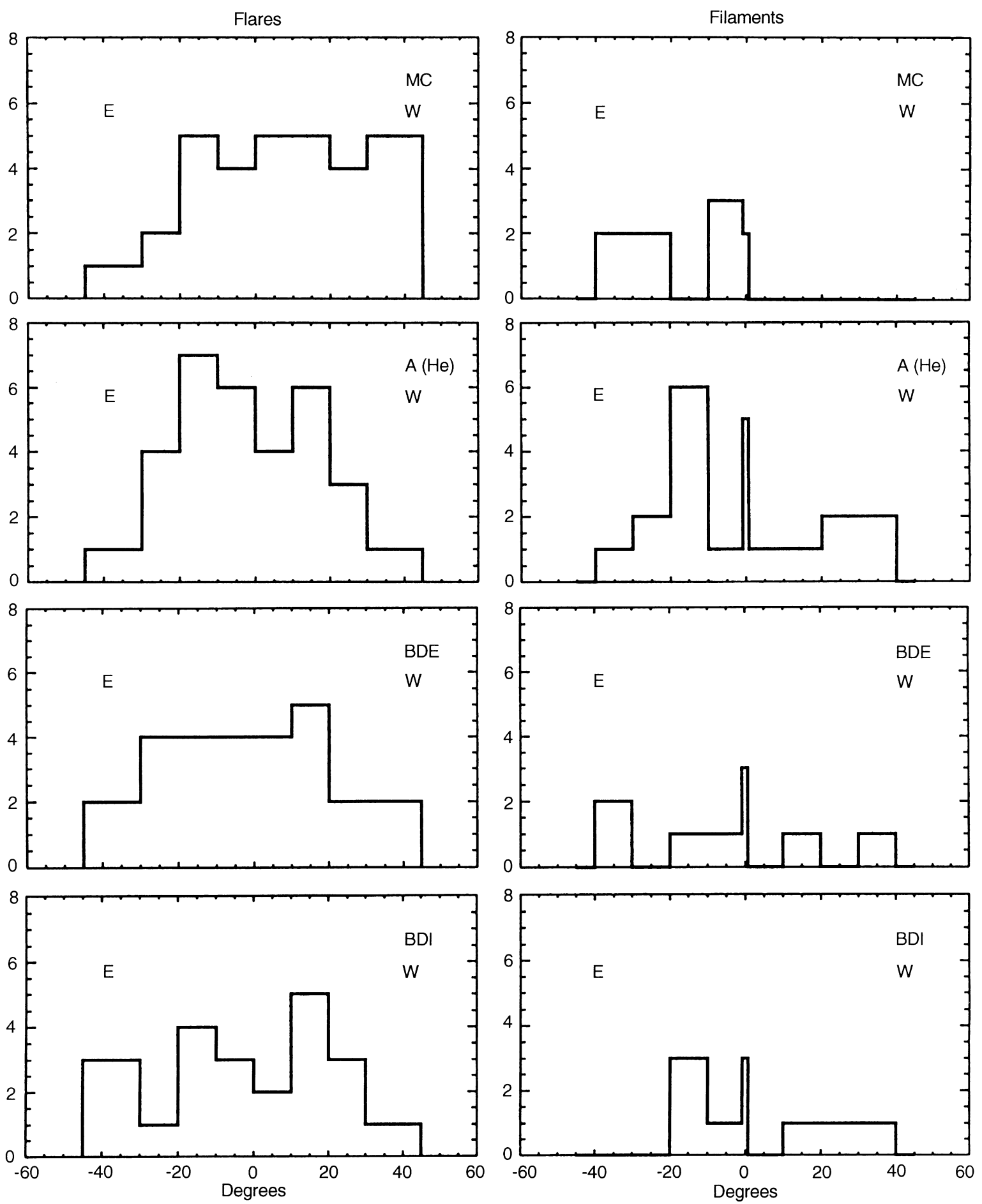

Fig. 2. Longitudinal distribution with respect to the solar central meridian of the solar events associated with each particular IP signature. In the case of filament eruptions the thin, black column at $0^{\circ}$ indicates the number of filaments that erupted while crossing the solar central meridian

only a small region in it, and in many occasions they appear without a cloud. All this indicates that the solar mass ejections leading to these signatures are, in general, complex processes involving the ejection of plasma from different regions of the Sun and probably at different times too, and that bidirectional streamings may originate outside the ejecta, probably as a result of the interaction of the ejecta with the ambient solar wind.
This agrees with the suggestion that bidirectional fluxes may be produced by magnetic mirrors in the interplanetary medium as suggested by Kahler and Reames (1991), Richardson and Cane (1993) and Vandas et al. (1996).

The physics of the solar origin of the signatures studied here has been addressed by other authors. Hirshberg (1972) associated helium enrichment events 
with the plasma of a flare site, as the presence of a high proportion of helium in the solar wind suggests the ejection of plasma from low regions in the corona. In our study, the majority of $\mathrm{A}(\mathrm{He})$ events are indeed related to flares, but there is also a good association with prominence eruptions. Several authors have suggested that magnetic clouds reflect the structure of a magnetic rope that constitutes a prominence or the coronal cavity where the prominence is immersed (e.g. Marubashi, 1986, 1997; Bothmer and Schwenn, 1994, 1997; Chen, 1996; Bothmer and Rust, 1997). A physical relation between clouds and flares has not been modelled, but in this case clouds might be associated with the twisted loops observed by Manoharan et al. (1997) expanding from flare sites. In our study the majority of clouds are associated with flares, in contrast to the study by Bothmer and Rust (1997) in which was found a much higher association with filament eruptions. One reason for this difference is that in some cases the filament associated by them was not reported as "disparition brusque" in the Meudon Catalogue that we used. Another reason is that they did not look for flares as we did, and in many occasions the flare event was more suitably associated with the IP transient in terms of the travelling time and the position on the solar disk (near the solar central meridian). A third difference is that our study concerns only magnetic clouds associated with transient interplanetary shocks, while Bothmer and Rust include many clouds that are not associated with shocks. Some magnetic clouds in our study $(7 \%)$ were not associated with any kind of surface explosive event, suggesting that there must be other ways of producing the signature of a magnetic cloud as, for example, by multiple magnetic reconnection of previously open field lines in interplanetary space, as has been suggested by Moldwin et al. (1995). It is possible that some of the plasma and field characteristics are different for clouds associated with filaments, flares or nothing, and depending on whether or not the cloud is accompanied by other IP signatures. A detailed study of the characteristics of magnetic clouds in relation to their solar and interplanetary associations is necessary and will be addressed in a future paper.

The high percentage of association with surface explosive events does not imply that every flare or filament eruption occurring near solar central meridian will be able to produce a signature in the solar wind. We have suggested (Bravo, 1996) that the presence of a coronal hole, a region where field lines are open, near the site of the surface explosive event, facilitates the access of the ejected plasma from below to the interplanetary medium. In this study we found that a coronal hole was beside the explosive event near central meridian in about $90 \%$ of the cases. This high percentage cannot just be a coincidence, as low-latitude coronal holes or low-latitude extension of polar coronal holes occupy very small regions covering, altogether, between $2 \%$ and $10 \%$ of the solar surface.

The high percentage of IP transients associated with $\mathrm{X}$-ray events, which most probably result from magnetic field line reconnection in the corona, reinforces the idea that solar mass ejections are the result of large-scale rearrangements of the coronal magnetic structures. However, in our study many IP transients are not associated with an X-ray event, most of these being clouds and helium enrichments. It is clear that more research is still needed to understand the mechanisms leading to each particular transient interplanetary signature and the role that flares and filament eruptions play in these processes. The analysis presented here does not intend to be exhaustive or conclusive, but our results show a variety of details not previously considered that can be useful to guide further studies.

Acknowledgements. We acknowledge the use of the OMNI-data base at NSSDC Greenbelt, Maryland, USA. This paper was partially supported by DGAPA Project IN-103996.

Topical Editor R. Schwenn thanks V. Bothmer and M. Vandas for their help in evaluating this paper.

\section{References}

Borrini, G., J. T. Gosling, S. J. Bame, and W. C. Feldman, An analysis of shock wave disturbances observed at 1 AU from 1971 through 1978, J. Geophys. Res., 87, 4365, 1982a.

Borrini, G., J. T. Gosling, S. J. Bame, and W. C. Feldman, Helium abundance enhancements in the solar wind, J. Geophys. Res., 87, 7370, 1982b.

Bothmer, V., and D. M. Rust, The field configuration of magnetic clouds and the solar cycle, in Coronal mass ejections, eds. N. Croocker, J.A. Jocelyn, and J. Feynman, AGU, Geophys. Monogr. 99, Washington D.C., p. 137, 1997.

Bothmer, V., and R. Schwenn, Magnetic clouds observations by the Helios spacecraft, in Solar Wind 7, Eds. E. Marsh and R. Schwenn, Pergamon Press, Oxford, p. 599, 1992.

Bothmer, V., and R. Schwenn, Eruptive prominences as sources of magnetic clouds in the solar wind, Space Sci. Rev., 70, 215, 1994.

Bothmer, V., and R. Schwenn, The structure and origin of magnetic clouds in the solar wind, Ann. Geophysicae, in press, 1997.

Bravo, S., A solar scenario for the associated occurrence of flares, eruptive prominences, coronal mass ejections, coronal holes, and interplanetary shocks, Solar Phys., 161, 57, 1995.

Bravo, S., The role of coronal holes in linking solar, interplanetary, and geomagnetic activity, in Solar drivers of interplanetary and terrestrial disturbances, Eds. K.S. Balasubramaniam, S.L. Kiel, and R.N. Smartt, Astronomical Society of the Pacific, California, p. 445, 1996.

Bravo, S., and M. Lanzagorta, Magnetic and plasma characteristics of the solar wind behind shocks, in Solar terrestrial energy program, Eds. D.N. Baker, V.O. Papitashvili, and M.J. Teague, Pergamon Press, Oxford, p. 227, 1994.

Burlaga, L. F., Compound streams, magnetic clouds, and major geomagnetic storms, J. Geophys. Res., 92, 5725, 1987.

Burlaga, L. F., Magnetic clouds, in Physics of the inner heliosphere (2), Eds. R. Schwenn and E. Marsh, Springer, Berlin, Heidelberg, New York, p. 1, 1991.

Burlaga, L. F., E. Sittler, F. Mariani, and R. Schwenn, Magnetic loop behind an interplanetary shock: Voyager, Helios, and IMP observations, J. Geophys. Res., 86, 6673, 1981.

Burlaga, L. F., L. W. Klein, N. R. Sheeley Jr., D. J. Michels, R. A. Howard, M. J. Koomen, R. Schwenn, and H. Rosenbauer, A magnetic cloud and a coronal mass ejection, Geophys. Res. Lett., 9, 1317, 1982.

Cane H. V., I. G. Richardson, and K. Harvey, Filament disappearances and associated shocks of May 1979, J. Geophys. Res., 96, 19525, 1991.

Chen, J., Theory of prominence eruption and propagation: interplanetary consequences, J. Geophys. Res., 101, 27499, 1996. 
Gosling, J. T., Coronal mass ejections and magnetic flux ropes in interplanetary space, in Physics of magnetic flux ropes, Eds. C.T. Russell, E. Priest, and L.C. Lee, Geophys. Monogr. 58, ALU, Washington D.C., p. 343, 1990.

Gosling, J. T., The solar flare myth, J. Geophys. Res., 98, 18937, 1993.

Gosling, J. T., E. Hilder, R. M. MacQueen, R. H. Munro, A. I. Poland, and C. L. Ross, Mass ejections from the sun: a view from Skylab, J. Geophys. Res., 79, 4581, 1974.

Gosling, J. T., J. R. Asbridge, S. J. Bame, W. C. Feldman, and R. D. Zwickl, Observations of large fluxes of $\mathrm{He}+$ in the solar wind following an interplanetary shock, J. Geophys. Res., 85, $3431,1980$.

Gosling, J. T., D. N. Baker, S. J. Bame, W. C. Feldman, R. D. Zwickl, and E. J. Smith, Bidirectional solar wind electron heat flux events, J. Geophys. Res., 92, 8519, 1987.

Gosling, J. T., S. J. Bame, D. J. McComas, and J. L. Phillips, Coronal mass ejections and large geomagnetic storms, Geophys. Res. Lett., 17, 99, 1990.

Hammond, C. M., W. C. Feldman, J. L. Phillips, and A. Balogh, Ulysses observations of double ion beams associated with coronal mass ejections, Adv. Space Res., 17(4/5), 303, 1996.

Harrison, R. A., A statistical study of the coronal mass ejection phenomena, Adv. Space Res., 14(4), 23, 1994.

Harvey, K., and N. R. Sheeley Jr., Coronal holes and solar magnetic fields, Space Sci. Rev., 23, 139, 1979.

Hewish, A., and S. Bravo, The sources of large-scale heliospheric disturbances, Solar Phys., 106, 185, 1986.

Hirshberg J., Solar wind helium enhancements following major solar flares, in Solar wind, Eds. C.P. Sonett, P.J. Coleman Jr., and J.M. Wilcox, NASA-JP308, p. 582, 1972.

Hirshberg J., A. Alksne, D. S. Colburn, S. J. Bame, and A. J. Hundhausen, Observation of a solar-flare-induced interplanetary shock and helium-enriched driver gas, J. Geophys. Res., 75, $1,1970$.

Hundhausen, A. J., Coronal expansion and solar wind, Springer, Berlin, Heidelberg, New York, 1972.

Joselyn, J. A., and P. S. MacIntosh, Disappearing solar filaments: a useful predictor of geomagnetic activity, J. Geophys. Res., 86, 4555,1981

Kahler, S. W., and D. V. Reames, Probing the magnetic topologies of magnetic clouds by means of solar energetic particles, $J$. Geophys. Res, 96, 9419, 1991.

Kallenrode, M. B., G. Wibberenz, H. Kunow, R. Muller-Mellin, V. Stolpovsku, and N. Kontor, Multi-spacecraft observations of particle events and interplanetary shocks during November/ December 1982, Solar Phys., 147, 377, 1993.

Klein, L. W., and L. F. Burlaga, Interplanetary magnetic clouds at 1 AU, J. Geophys. Res, 87, 613, 1982.

Lindsay, G. M., C. T. Russel, and J. G. Luhmann, Coronal mass ejection and stream interaction region characteristics and their potential geomagnetic effectiveness, J. Geophys. Res, 100, $16999,1995$.

Manoharan, P. K., L. van Driel-Gesztelyi, M. Pick, and P. Démoulin, Evidence for a large-scale solar magnetic reconnection from radio and X-ray measurements, Astrophys. J., in press, 1997.

Marsden, R. G., T. R. Sanderson, K. P. Wenzel, and E. J. Smith, ISEE 3 observations of low-energy proton bidirectional events and their relation to isolated interplanetary magnetic structures, J. Geophys. Res, 92, 11009, 1987.
Marubashi, K., Structure of the interplanetary magnetic clouds and their solar origin, Adv. Space Res., 6(6), 335, 1986.

Marubashi, K., Interplanetary magnetic flux ropes and solar filaments, in Coronal mass ejections: causes and consequence, Eds. N. Crooker, J. Joselyn, J. Feynman, AGU Monograph, in press, 1997.

McComas, D. J., J. T. Gosling, S. J. Bame, E. J. Smith, and H. V. Cane, A test of magnetic field drapping induced Bz perturbations ahead of fast coronal mass ejecta, J. Geophys. Res, 94, $1465,1989$.

Moldwin, M. B., J. L. Phillips, J. T. Gosling, E. E. Scime, D. J. McComas, S. J. Bame, A. Balogh, and R. J. Forsyth, Ulysses observation of a noncoronal mass ejection flux rope: evidence of interplanetary magnetic reconnection, J. Geophys. Res., 100, $19903,1995$.

Richardson, I. G., and H. V. Cane, Signatures of shock drivers in the solar wind and their dependence on the solar source location, J. Geophys. Res., 98, 15295, 1993.

Rust, D. M., Spawning and shedding helical magnetic fields in the solar atmosphere, Geophys. Res. Lett., 21, 241, 1994.

Schwenn, R., Mass ejections from the sun and their interplanetary counterparts, in Solar wind eight, Eds. D. Winterhalter, J. T. Gosling, S. R. Habbal, W. S. Kurth, and M. Neugebauer, AIP Conference proceedings 382, AIP Press, New York, p. 426, 1996.

Sheeley, N. R., Jr., R. A. Howard, M. J. Koomen, and D. J. Michels, Associations between coronal mass ejections and soft X-ray events, Astrophys. J., 272, 349, 1983.

Sheeley, N. R., Jr., R. A. Howard, M. J. Koomen, D. J. Michels, R. Schwenn, K. H. Mulhauser, and H. Rosenbauer, Coronal mass ejections and interplanetary shocks, J. Geophys. Res., 90, 163, 1985.

Stewart, R. T., H. C. M. Evson, and L. H. Heisler, Culgoora catalogue of solar radio noise storms, 1973 to 1984, Proc. ASA, 6, 231, 1985.

Tang, F., B. T. Tsurutani, W. D. Gonzalez, S. I. Akasofu, and E. J. Smith, Solar sources of interplanetary southward Bz events responsible for major magnetic storms (1978-1979). J. Geophys. Res., 94, 3535, 1989.

Tousey, R., The solar corona, Adv. Space Res., 13, 713, 1973

Vandas, M., S. Fischer, A. Geranios, M. Dryer, Z. Smith, and T. Detman, Magnetic traps in the interplanetary medium associated with magnetic clouds, J. Geophys. Res., 101, 21589, 1996.

Wagner, W. J., Coronal mass ejections, Ann. Rev. Astron. Astrophys., 22, 267, 1984.

Webb, D. F., and A. J. Hundhausen, Activity associated with the solar origin of coronal mass ejections, Solar Phys. 108, 383, 1987.

Webb, D, B. Jackson, P. Hick, R. Schwenn, V. Bothmer, and D. Reames, Comparison of CMEs, magnetic clouds, and bidirectional streaming proton events in the heliosphere using Helios data, Adv. Space Res., 13 (9), 71, 1993.

Wilson, R. M., and E. Hildner, On the association of magnetic clouds with disappearing filaments, J. Geophys. Res., 91, 5867, 1986.

Zhang, G., and L. F. Burlaga, Magnetic clouds, geomagnetic disturbances and cosmic ray decreases, J. Geophys. Res., 93, 2511, 1988.

Zwickl, R. D., J. R. Asbridge, S. J. Bame, W. C. Feldman, J. T. Gosling, and E. J. Smith, Plasma properties of driver gas following interplanetary shocks observed by ISEE-3, in Solar Wind Five, Ed. M. Neugebauer, NASA CP-2280, p. 711, 1983. 